\title{
Application value of procalcitonin, $C$-reactive protein and interleukin-6 in the evaluation of traumatic shock
}

\author{
YANG LI ${ }^{1}$, LING CHEN $^{2}$, WENGE FANG ${ }^{2}$ and HUIHONG CHEN ${ }^{2}$ \\ ${ }^{1}$ Department of Emergency, Zhangzhou Affiliated Hospital of Fujian Medical University; \\ ${ }^{2}$ Department of Emergency, Zhangzhou Municipal Hospital of Fujian Province, \\ Zhangzhou, Fujian 363000, P.R. China
}

Received November 26, 2018; Accepted April 2, 2019

DOI: $10.3892 /$ etm.2019.7492

\begin{abstract}
Procalcitonin (PCT), C-reactive protein (CRP) and interleukin-6 (IL-6) were detected to explore the value of these inflammatory markers in the assessment of traumatic shock patients. The clinical data of 80 patients with traumatic shock and infections in Zhangzhou Municipal Hospital of Fujian Province from January 2014 to December 2017 were collected as the experimental group. During the same period, 80 acute trauma patients who did not suffer from traumatic shock were regarded as the control group. According to the prognosis outcomes, the experimental group was divided into 56 patients with good prognosis and 24 patients with poor prognosis. Also the PCT, CRP and IL-6 levels in serum of patients at admission (T1), $12 \mathrm{~h}$ after admission (T2), three days after admission (T3) and on day 7 (T4) were detected. The differences between the three inflammatory indicators, the pre-admission injury severity score (ISS score), the acute physiology and chronic psychological score (APACHE II score) were compared between the good prognosis and the poor prognosis group. The serum CRP at the T4 time period was significantly lower than both the $\mathrm{T} 1$ and $\mathrm{T} 2$ time periods $(\mathrm{P}<0.05)$. There were differences in serum PCT, CRP and IL-6 between the good prognosis and the poor prognosis group at the time of T1-T4 $(\mathrm{P}<0.05)$. The expression levels of PCT, CRP and IL-6 in the serum of patients with poor prognosis were higher than those with good prognosis $(\mathrm{P}<0.05)$. Pre-admission ISS scores and APACHE II scores in patients with good prognosis were lower than those with poor prognosis $(\mathrm{P}<0.05)$. Detection of PCT, CRP and IL-6 expression levels in serum of the patients has an important reference value for assessing the condition of patients with traumatic shock.
\end{abstract}

Correspondence to: Dr Yang Li, Department of Emergency, Zhangzhou Affiliated Hospital of Fujian Medical University, 59 Shengli West Road, Zhangzhou, Fujian 363000, P.R. China E-mail: u5y9wn@163.com

Key words: procalcitonin, C-reactive protein, interleukin-6, traumatic shock, application value

\section{Introduction}

The rhythm of life in modern society is constantly accelerating with endless social conflicts, fighting, traffic accidents, natural disasters and man-made disasters which have led to an increased number of trauma patients (1). Among them, the shock that is caused by violent trauma has become a critical clinical emergency (2). Compared with ordinary traumatic hemorrhage, traumatic shock is more complicated and has a more rapid disease progression (3). Accurately determining the severity of a patient's trauma at an early stage and prompt treatment of patients in a timely manner have become very important for the prognosis of patients.

Procalcitonin (PCT) is a protein that reflects the activity of the body's inflammatory response (4). High expression occurs in sepsis, shock, and multiple organ dysfunctions $(5,6)$. C-reactive protein (CRP), an acute protein, is sensitive to tissue damage and microbial infections (7). Both are inflammatory indicators commonly used in the diagnosis and treatment of clinically acute diseases. Interleukin-6 (IL-6) is an inflammatory factor that can coordinate with the body's immune response after injury (8). Studies have shown that IL- 6 can reflect the degree of tissue damage in the body to some extent (9). The current clinical diagnosis and treatment of patients with traumatic shock mainly depend on the monitoring of hemodynamic parameters, however, these judgments on the degree of traumatic shock in patients are still insufficient (10). Therefore, in this study we focused on the analysis of PCT, CRP and IL-6 expression levels in the serum of traumatic shock patients, and explored the value of the three in the assessment of the condition in traumatic shock patients.

\section{Patients and methods}

General information. A total of 80 cases of traumatic shock patients who were in the emergency surgery in Zhangzhou Municipal Hospital of Fujian Province (Zhangzhou, China) from January 2014 to December 2017 were retrospectively collected as the experimental group, including 42 males and 38 females, aged 51-72 years, average age 52.78 \pm 4.67 years. Further 80 patients with general trauma who did not suffer from shock during the same period were selected as the control group, including 45 males and 35 females, aged 48-73 years, 
average age $53.68 \pm 4.95$ years. According to the prognosis outcome of the patients, the experimental components were divided into good prognosis and poor prognosis group. There were 56 cases in the good prognosis and 24 cases in the poor prognosis group.

Inclusion criteria were: i) All subjects were over 18 years old, have not been traumatized recently, and have not undergone surgery; ii) patients in the experimental group met the diagnostic criteria for traumatic shock (11); iii) patients in control group had no disturbance of consciousness and their hemodynamic parameters were normal, with no signs of shock; iv) patients in the good prognosis group showed a significant improvement in their disease condition after admission, and can be discharged within 30 days, no adverse events occurred such as death, multiple organ dysfunction syndrome; and v) adverse events such as death or multiple organ dysfunction syndrome occurred to patients in the poor prognosis group. Total treatment in the intensive care unit took more than 30 days.

Exclusion criteria were: i) Subjects with history of hypertension, chronic disease of diabetes or coagulopathy; ii) patients with heart and blood vessel diseases, hepatic and renal dysfunction and adverse reaction during transfusion; and iii) patients with incomplete medical data.

The study was approved by the Ethics Committee of Zhangzhou Municipal Hospital of Fujian Province. Patients who participated in this study had complete clinical data. Signed informed consents were obtained from the patients or the guardians.

Experimental reagents and instruments. Ultra-low temperature refrigerator (Premium U410; Suzhou Beirui Instrument Technology Co., Ltd., Suzhou, China); Human PCT ELISA kit (FK-pk0812; Shanghai Fanke Biotechnology Co., Ltd., Shanghai, China); IL-6 ELISA kit [JK-(a)-0023; Shanghai Jingkang Bioengineering Co., Ltd., Shanghai, China]; Automatic microplate reader (26262002; Beijing Anmaige Trading Co., Ltd., Beijing, China); High-speed refrigerated centrifuge [AVANTI J-15R; Beckman Coulter Trading (China) Co., Ltd., Shanghai, China]; Ultra-micro spectrophotometer (NP80-Touch; Guangzhou Haohan Instrument Co., Ltd., Guangzhou, China); CRP assay kit (XFSW245B; Shanghai Xinfan Biotechnology Co., Ltd., Shanghai, China); Micro-adjustable pipette (F144565; Shenzhen Kangchuyuan Co., Ltd., Shenzhen, China).

\section{Experimental methods}

Collection of blood samples. During the period of fasting, the patients' elbow venous blood $(2 \mathrm{ml})$ were collected with a disposable blood collection needle immediately after the admission (T1), and on the first (T2), third (T3), seventh (T4) day after admission. The blood was naturally coagulated for 10-20 min at room temperature, then centrifuged at 3,000 x g for $20 \mathrm{~min}$ at $4^{\circ} \mathrm{C}$. After the serum was naturally precipitated, the supernatant was carefully pipetted into another clean tube and the tube was place at $-80^{\circ} \mathrm{C}$ in a freezer for further testing.

Determination of PCT and IL-6 expression levels in serum by enzyme-linked immunosorbent assay (ELISA). The expression levels of PCT and IL- 6 in patients' serum by ELISA were tested by double antibody sandwich assay. Standard, blank and sample wells were set on an enzyme plate. The standards were diluted to $1.0-2.0 \mu \mathrm{g} / \mathrm{ml}$ with diluent, and each well was added with $50 \mu \mathrm{l}$ dilution. Then $40 \mu \mathrm{l}$ sample dilution was added to the sample wells of the enzyme plate, and $10 \mu \mathrm{l}$ of samples was added for further testing. Avoiding touching the surrounding walls loading was done, and then gently shaken. Then the enzyme plate was sealed with a sealing membrane, and incubated at $37^{\circ} \mathrm{C}$ for $30 \mathrm{~min}$. Next, the sealing membrane was uncovered and the liquid discarded in the well and each well was washed 5 times with the diluted washing solution. Except the blank wells, $50 \mu \mathrm{l}$ of the enzyme standard reagent was added to each well, the plate was sealed with a sealing membrane, and incubated for $30 \mathrm{~min}$, then the liquid was discarded in each well and washed 5 times. Then $50 \mu \mathrm{l}$ of chromogenic reagent $\mathrm{A}$ and $50 \mu \mathrm{l}$ of chromogenic reagent $\mathrm{B}$ was added to each well. After shaking, protected from light stained at a temperature of $37^{\circ} \mathrm{C}$ for $15 \mathrm{~min}$. Finally, $50 \mu \mathrm{l}$ of stop solution was added to each well, the blank well was zero in value, the OD value in each well was measured at a wavelength of $450 \mathrm{~nm}$ in $15 \mathrm{~min}$.

Determination of CRP expression levels in patient serum by immunoturbidimetry. A sample of $100 \mu \mathrm{l}$ was mixed with reagent (R1-3), adding $\mathrm{R} 4$, and centrifuged at 3,000 x $\mathrm{g}$ for $10 \mathrm{~min}$ at $4^{\circ} \mathrm{C}$, then the supernatant was pipetted into another tube, adding chromogenic reagent, and R6, then left at room temperature for $2 \mathrm{~min}$. After $5 \mathrm{~min}$ the OD value was measured at a wavelength of $636 \mathrm{~nm}$.

Observation of indices. The expression levels of PCT, CRP and IL- 6 in the serum in the control group with the good and the poor prognosis were recorded at the T1-T4 time periods. Also the injury severity score (ISS) (12) between the good and the poor prognosis before admission, and the score of acute pathologic and chronic health evaluation (APACHE II) during the period of T1-T4 were recorded (13).

Statistical analysis. The experimental data were statistically analyzed by SPSS 19.0 statistical software (SPSS, Inc., Chicago, IL, USA), the data counting was expressed as percentages (\%), the Chi-square test was used for comparison between groups, measurement data was expressed by mean \pm standard deviation, the t-test was used for comparison between groups, repeated measures analysis of variance was used for comparison of multiple time points between groups with Dunnett's test. One-way ANOVA was used for comparison between groups. $\mathrm{P}<0.05$ was considered to indicate a statistically significant difference.

\section{Results}

Comparison of general information. As shown in Table I, 48 cases of trauma in the experimental group were caused by traffic accidents, 19 cases were caused by fall injury, 10 cases were caused by sharp injury and 3 cases were caused by other factors. Trauma time (30 sec-1.2 h), average $1.17 \pm 0.16 \mathrm{~h}$. In the control group, there were 46 cases of traffic accidents, 18 cases of fall injuries, 9 cases of sharp injuries and 7 cases of others. Trauma time (50 sec-1.3 h), average $1.12 \pm 0.21 \mathrm{~h}$. There were 
Table I. Comparison of general clinical basic information $[\mathrm{n}(\%)]($ mean \pm standard deviation).

\begin{tabular}{|c|c|c|c|c|}
\hline Clinical factors & Experiment group $(\mathrm{n}=80)$ & Control group $(\mathrm{n}=80)$ & $t / \chi^{2}$ & P-value \\
\hline Age (years) & $52.78 \pm 4.67$ & $53.68 \pm 4.95$ & 1.183 & 0.239 \\
\hline $\operatorname{BMI}\left(\mathrm{kg} / \mathrm{m}^{2}\right)$ & $23.67 \pm 2.82$ & $23.79 \pm 2.53$ & 0.283 & 0.777 \\
\hline Sex & & & 0.227 & 0.634 \\
\hline Male & 42 & 45 & & \\
\hline Female & 38 & 35 & & \\
\hline Causes of injury & & & 1.722 & 0.632 \\
\hline Traffic accident & 48 & 46 & & \\
\hline Fall injury & 19 & 18 & & \\
\hline Sharp injury & 10 & 9 & & \\
\hline Others & 3 & 7 & & \\
\hline Blood sugar (mmol/l) & & & 0.526 & 0.468 \\
\hline$<6.11$ & 75 & 77 & & \\
\hline$\geq 6.11$ & 5 & 3 & & \\
\hline Triglyceride $(\mathrm{mmol} / \mathrm{l})$ & & & 0.278 & 0.598 \\
\hline$<1.70$ & 73 & 71 & & \\
\hline$\geq 1.70$ & 7 & 9 & & \\
\hline Trauma time (h) & $1.17 \pm 0.16$ & $1.12 \pm 0.21$ & 1.694 & 0.092 \\
\hline
\end{tabular}

Blood glucose and triglycerides were measured at the time of admission.

Table II. Comparison of PCT in serum.

\begin{tabular}{|c|c|c|c|c|c|c|}
\hline Variables & $\mathrm{T} 1$ & $\mathrm{~T} 2$ & T3 & $\mathrm{T} 4$ & $\mathrm{~F}$ & P-value \\
\hline Control group $(n=80)$ & $0.52 \pm 0.06$ & $0.55 \pm 0.12$ & $0.53 \pm 0.08$ & $0.54 \pm 0.11$ & 1.461 & 0.225 \\
\hline Good prognosis group $(n=56)$ & $3.79 \pm 1.83^{\mathrm{d}}$ & $4.21 \pm 2.36^{\mathrm{d}}$ & $9.14 \pm 3.74^{\mathrm{a}, \mathrm{b}, \mathrm{d}}$ & $4.83 \pm 1.24^{\mathrm{c}, \mathrm{d}}$ & 55.86 & $<0.001$ \\
\hline Poor prognosis group $(n=24)$ & $7.93 \pm 2.49^{\mathrm{d}, \mathrm{e}}$ & $14.38 \pm 3.58^{\mathrm{add}, \mathrm{e}}$ & $11.68 \pm 5.26^{\mathrm{a}, \mathrm{d}, \mathrm{e}}$ & $9.46 \pm 3.73^{\mathrm{b}, \mathrm{d}, \mathrm{e}}$ & 12.250 & $<0.001$ \\
\hline $\mathrm{F}$ & 264.600 & 461.300 & 198.700 & 215.400 & & \\
\hline P-value & $<0.001$ & $<0.001$ & $<0.001$ & $<0.001$ & & \\
\hline
\end{tabular}

Within the same group: ${ }^{\mathrm{a}} \mathrm{P}<0.05$, compared with $\mathrm{T} 1$; ${ }^{\mathrm{b}} \mathrm{P}<0.05$, compared with $\mathrm{T} 2$; ${ }^{\mathrm{c}} \mathrm{P}<0.05$, compared with $\mathrm{T} 3$. At the same time point: ${ }^{\mathrm{d}} \mathrm{P}<0.05$, compared with the control group; ${ }^{\mathrm{e}} \mathrm{P}<0.05$, compared with the good prognosis group. PCT, procalcitonin.

no differences in age, body mass index, sex, cause of injury and time of trauma between the experimental and the control group $(\mathrm{P}>0.05)$.

Comparison of PCT in serum among the experimental, the good and poor prognosis group. There was no significant difference in serum PCT in the control group at the period of T1-T4 ( $\mathrm{P}>0.05)$. There was a difference in serum PCT between the good prognosis and the poor prognosis group at the period of T1-T4 $(\mathrm{P}<0.05)$. Serum PCT levels of T2, T3 were significantly increased compared with the period of $\mathrm{T} 1$ in the poor prognosis group $(\mathrm{P}<0.05)$. Compared with the period of $\mathrm{T} 2$, T3 was significantly increased in good prognosis group, and the period of T4 was significantly decreased in poor prognosis group $(\mathrm{P}<0.05)$. Compared with the period of $\mathrm{T} 3$, T4 was significantly decreased in good prognosis group $(\mathrm{P}<0.05)$. At the same time point, both good prognosis and poor prognosis groups were higher than the control group. The poor prognosis group was higher than the good prognosis group $(\mathrm{P}<0.05$; Table II and Fig. 1).

Comparison of serum CRP among the experimental, the good prognosis and poor prognosis groups. There was no significant difference in serum CRT in the control group at the period of T1-T4 ( $\mathrm{P}>0.05)$. There was a difference in serum CRP between the good prognosis and the poor prognosis groups at the period of T1-T4 $(\mathrm{P}<0.05)$. Compared with $\mathrm{T} 1, \mathrm{~T} 3$ was significantly increased in the poor prognosis group $(\mathrm{P}<0.05)$. The poor prognosis has significantly decreased at T2-T4 time periods $(\mathrm{P}<0.05)$. Compared with the period of $\mathrm{T} 2$, $\mathrm{T} 4$ was significantly decreased in the good prognosis group, and the period of T3 was significantly increased in the poor prognosis group $(\mathrm{P}<0.05)$. Compared with the period of T3, T4 was significantly decreased in both good prognosis and poor prognosis groups $(\mathrm{P}<0.05)$. 
Table III. Comparison of CRP in serum.

\begin{tabular}{|c|c|c|c|c|c|c|}
\hline Variables & $\mathrm{T} 1$ & $\mathrm{~T} 2$ & $\mathrm{~T} 3$ & $\mathrm{~T} 4$ & $\mathrm{~F}$ & P-value \\
\hline Control group $(n=80)$ & $12.88 \pm 1.41$ & $12.78 \pm 1.23$ & $12.47 \pm 1.13$ & $12.13 \pm 1.12^{\mathrm{a}, \mathrm{b}}$ & 6.078 & 0.001 \\
\hline Good prognosis group $(n=56)$ & $126.37 \pm 31.73^{\mathrm{d}}$ & $110.42 \pm 30.24^{\mathrm{a}, \mathrm{d}}$ & $98.45 \pm 28.63^{\mathrm{a}, \mathrm{d}}$ & $83.34 \pm 24.82^{\mathrm{a}-\mathrm{d}}$ & 24.190 & $<0.001$ \\
\hline Poor prognosis group $(n=24)$ & $131.68 \pm 29.37^{\mathrm{d}, \mathrm{e}}$ & $142.58 \pm 35.41^{\mathrm{d}, \mathrm{e}}$ & $173.60 \pm 36.19^{\mathrm{a}, \mathrm{b}, \mathrm{d}, \mathrm{e}}$ & $128.32 \pm 31.23^{\mathrm{c}-\mathrm{e}}$ & 9.275 & $<0.001$ \\
\hline $\mathrm{F}$ & 565.500 & 473.300 & 590.000 & 446.700 & & \\
\hline P-value & $<0.001$ & $<0.001$ & $<0.001$ & $<0.001$ & & \\
\hline
\end{tabular}

Within the same group: ${ }^{\mathrm{a}} \mathrm{P}<0.05$, compared with $\mathrm{T} 1$; ${ }^{\mathrm{b}} \mathrm{P}<0.05$, compared with $\mathrm{T} 2$; ${ }^{\mathrm{C}} \mathrm{P}<0.05$, compared with $\mathrm{T} 3$. At the same time point, ${ }^{\mathrm{d}} \mathrm{P}<0.05$, compared with the control group, ${ }^{\mathrm{e}} \mathrm{P}<0.05$ compared with good prognosis group. CRP, C-reactive protein.

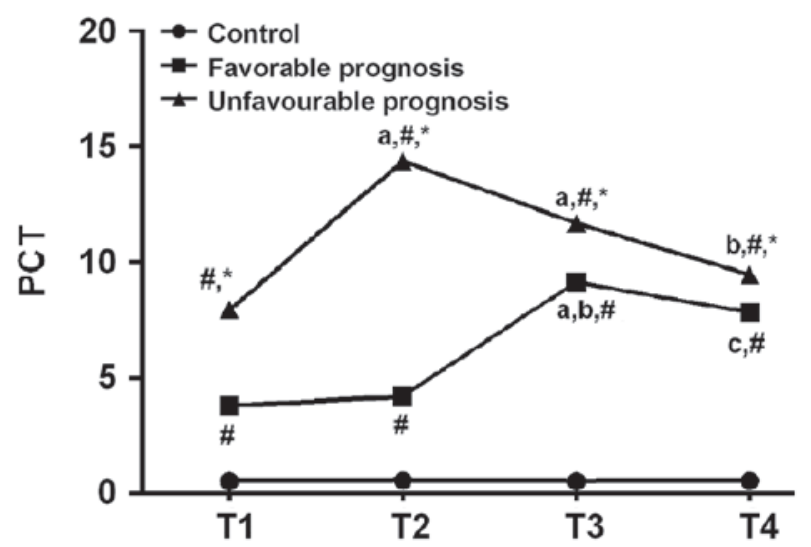

Figure 1. Comparison of PCT in serum among the experimental group with good prognosis and poor prognosis groups. There was no significant difference in serum PCT in the control group at T1-T4 time period $(\mathrm{P}>0.05)$. There was a difference in serum PCT between good prognosis and poor prognosis group at T1-T4 $(" \mathrm{P}<0.05)$. At the same time point, $\mathrm{PCT}$ values for both good prognosis and poor prognosis groups were higher than the PCT values of control group $\left({ }^{*} \mathrm{P}<0.05\right)$. The PCT values of poor prognosis group were higher than the PCT values of good prognosis group ("P<0.05). Within the same group: ${ }^{\mathrm{a}} \mathrm{P}<0.05$, compared with $\mathrm{T} 1$; ${ }^{\mathrm{b}} \mathrm{P}<0.05$, compared with $\mathrm{T} 2$; ${ }^{\mathrm{c}} \mathrm{P}<0.05$, compared with $\mathrm{T} 3$. $\mathrm{PCT}$, procalcitonin.

At the same time point, both the good prognosis and the poor prognosis groups were higher than the control group. Serum CRP in the poor prognosis group was higher than the good prognosis group at T2-T4 ( $\mathrm{P}<0.05$; Table III and Fig. 2).

Comparison of serum IL-6 among the experimental group with the good prognosis and poor prognosis group. There was no significant difference in serum IL- 6 between the control group at T1-T4 time period ( $\mathrm{P}>0.05)$. There was a difference in serum IL-6 between the good prognosis and the poor prognosis groups at the time of T1-T4 $(\mathrm{P}<0.05)$. Compared with the period of $\mathrm{T} 1, \mathrm{~T} 2$ in good prognosis group and $\mathrm{T} 3$ in poor prognosis group increased significantly $(\mathrm{P}<0.05)$. Both good and poor prognosis groups were decreased significantly at the $\mathrm{T} 4$ time period $(\mathrm{P}<0.05)$. Compared with the the period of $\mathrm{T} 2, \mathrm{~T} 4$ was significantly decreased in good prognosis group $(\mathrm{P}<0.05)$. Compared with the period of T3, T4 was significantly decreased in both good and poor prognosis groups $(\mathrm{P}<0.05)$. At the same time point, both good and poor prognosis groups were higher than the control group. Also poor prognosis group was higher than good prognosis group ( $\mathrm{P}<0.05$; Table IV and Fig. 3).

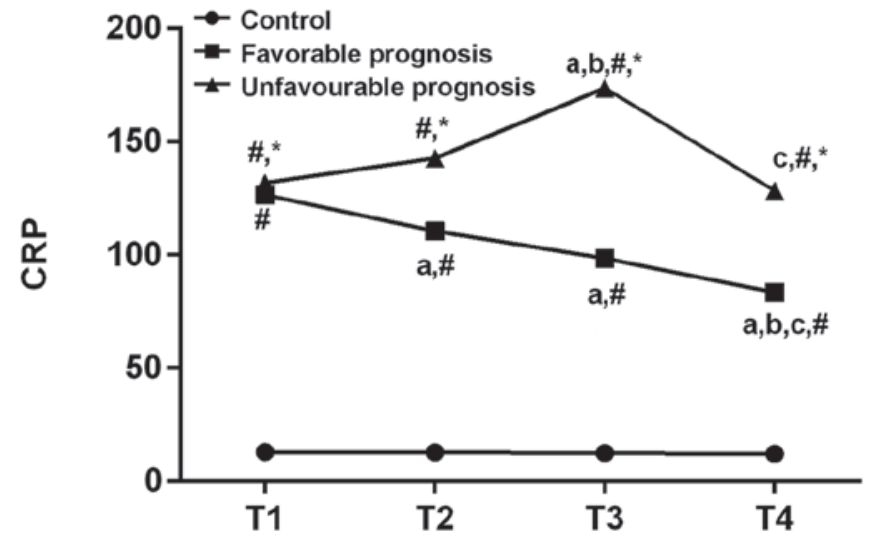

Figure 2. Comparison of serum CRP among the experimental group with good prognosis and poor prognosis groups. There was no significant difference in serum CRT in the control group at the period of T1-T4 $(\mathrm{P}>0.05)$. There was a difference in serum CRP between good prognosis and poor prognosis group at T1-T4 $\left({ }^{*} \mathrm{P}<0.05\right)$. At the same time point, CRP values for both good prognosis and poor prognosis groups were higher than the CRP values of control group $\left({ }^{\sharp} \mathrm{P}<0.05\right)$. The CRP values of poor prognosis group were higher than the CRP values of good prognosis group $\left({ }^{*} \mathrm{P}<0.05\right)$. Within the same group: a $\mathrm{P}<0.05$, compared with $\mathrm{T} 1$; ${ }^{\text {b }} \mathrm{P}<0.05$, compared with $\mathrm{T} 2$; ${ }^{\mathrm{c}} \mathrm{P}<0.05$ compared with T3. CRP, C-reactive-protein.

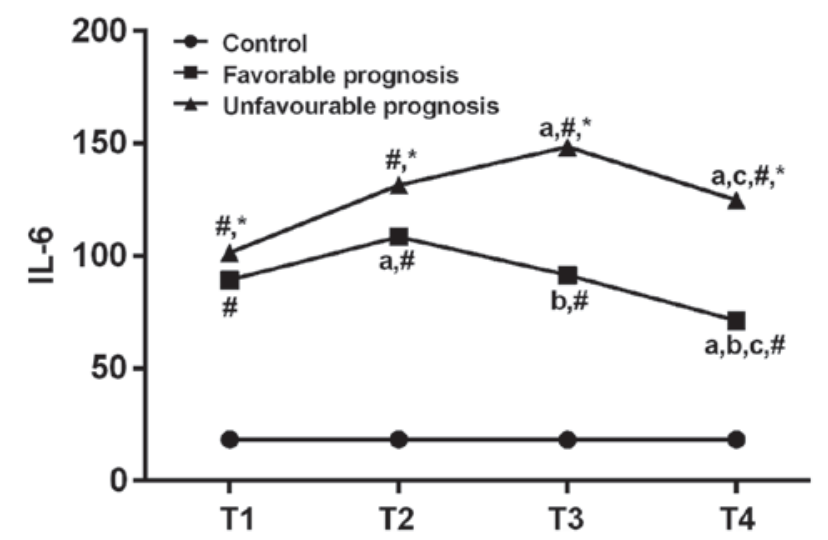

Figure 3. Comparison of serum IL-6 levels among the experimental group with good prognosis and poor prognosis groups. There was no significant difference in serum IL- 6 between the control group at the T1-T4 time period $(\mathrm{P}>0.05)$. There was a difference in serum IL-6 between the good prognosis and the poor prognosis group at the time of T1-T4 $\left({ }^{*} \mathrm{P}<0.05\right)$. At the same time point, IL-6 values for both good prognosis and poor prognosis groups were higher than IL- 6 values of control group $\left({ }^{\sharp} \mathrm{P}<0.05\right)$. IL- 6 values of poor prognosis group were higher than IL- 6 values of good prognosis group $\left({ }^{*} \mathrm{P}<0.05\right)$. Within the same group: ${ }^{\text {a }} \mathrm{P}<0.05$, compared with $\mathrm{T} 1$; ${ }^{\text {b }} \mathrm{P}<0.05$, compared with $\mathrm{T} 2$; ${ }^{\mathrm{P}}<0.05$, compared with T3. IL-6, interleukin-6. 
Table IV. Comparison of IL-6 in serum.

\begin{tabular}{lccccrr}
\hline Variables & $\mathrm{T} 1$ & $\mathrm{~T} 2$ & $\mathrm{~T} 3$ & $\mathrm{~T} 4$ & $\mathrm{~F}$ & P-value \\
\hline Control group $(\mathrm{n}=80)$ & $18.38 \pm 3.25$ & $18.49 \pm 3.16$ & $18.21 \pm 3.21$ & $18.13 \pm 3.22$ & 0.206 & 0.892 \\
Good prognosis group $(\mathrm{n}=56)$ & $89.30 \pm 17.91^{\mathrm{d}}$ & $108.46 \pm 12.43^{\mathrm{a}, \mathrm{d}}$ & $91.35 \pm 10.62^{\mathrm{b}, \mathrm{d}}$ & $71.25 \pm 6.21^{\mathrm{a}-\mathrm{d}}$ & 82.770 & $<0.001$ \\
Poor prognosis group $(\mathrm{n}=24)$ & $101.38 \pm 21.64^{\mathrm{d}, \mathrm{e}}$ & $131.48 \pm 31.56^{\mathrm{d}, \mathrm{e}}$ & $148.44 \pm 38.12^{\mathrm{a}, \mathrm{d}, \mathrm{e}}$ & $124.76 \pm 28.52^{\mathrm{a}, \mathrm{c}-\mathrm{e}}$ & 9.780 & $<0.001$ \\
F & 603.200 & 937.00 & 739.000 & 868.500 & & \\
P-value & $<0.001$ & $<0.001$ & $<0.001$ & $<0.001$ & &
\end{tabular}

Within the same group: ${ }^{\text {a }} \mathrm{P}<0.05$, compared with $\mathrm{T} 1$; ${ }^{\mathrm{P}} \mathrm{P}<0.06$, compared with $\mathrm{T} 2$; ${ }^{\mathrm{c}} \mathrm{P}<0.05$, compared with $\mathrm{T} 3$. At the same time point: ${ }^{\mathrm{d}} \mathrm{P}<0.06$, compared with the control group; ${ }^{\mathrm{e}} \mathrm{P}<0.05$, compared with the good prognosis group. IL, interleukin.

Table V. Comparison of ISS score and APACHE II score.

\begin{tabular}{lcccc}
\hline Variables & Good prognosis group $(\mathrm{n}=56)$ & Poor prognosis group $(\mathrm{n}=24)$ & $\mathrm{t}$ & P-value \\
\hline Pre-admission ISS scores & $15.82 \pm 4.24$ & $30.23 \pm 7.38$ & 11.020 & $<0.001$ \\
APACHE II scores & & & & \\
T1 & $18.38 \pm 5.21$ & $24.45 \pm 8.29$ & 3.963 & $<0.001$ \\
T2 & $16.24 \pm 4.63$ & $26.36 \pm 5.52$ & 5.657 & $<0.001$ \\
T3 & $15.37 \pm 3.94$ & $29.74 \pm 5.83$ & 12.860 & $<0.001$ \\
T4 & $13.45 \pm 3.21$ & $31.39 \pm 6.38$ & 16.750 & $<0.001$ \\
\hline
\end{tabular}

Comparison of ISS score and APACHE II score of patients in the good prognosis and the poor prognosis groups. As shown in Table V, there were differences in pre-admission ISS scores and APACHE II scores between the good prognosis and the poor prognosis groups. The pre-admission ISS score and APACHE II score in the good prognosis group were lower than in the poor prognosis group $(\mathrm{P}<0.05)$.

\section{Discussion}

Traumatic shock is a common emergency with rapid progression, the effective circulation of blood will decrease sharply after the body suffers from violence, this can lead to a syndrome of hypoperfusion of the microcirculation (14). During the progress of trauma treatment, if not treated in a timely manner, can lead to systemic inflammatory response syndrome or multiple organ dysfunction syndrome, which further cause the failure of multiple organs or systems, and patients can die within $10 \mathrm{~min}(15)$.

There is a clear standard for clinical diagnosis of whether a patient suffer from shock or not (16), however, there is still no clear indicator for the judgment of the shock severity in patients, only relying on physical examination and changes in hemodynamic parameters (17). Timely assessment of the patient's inflammatory response and infection status is important for the survival of traumatic shock patients (18), currently, PCT, CRP and IL- 6 are widely used acute wound proteins and cellular immune factors with high sensitivity in the body's inflammatory response (19). However, there is scarce research on the application value of PCT, CRP and IL- 6 in assessing the condition of patients with traumatic shock, therefore, this topic is focused on in our present study.
The results of this study have shown that the changes of PCT and IL-6 in serum at the time period of T1-T4 were not significant in the control group. The serum CRP at the T4 time period was lower than the $\mathrm{T} 1$ and $\mathrm{T} 2$ time periods. There were significant differences in serum PCT, CRP and IL- 6 between the good prognosis and the poor prognosis groups during the T1-T4 time period. At the same time points, both the good prognosis and the poor prognosis groups were higher than the control group and the poor prognosis group was higher than the good prognosis group. Also the pre-admission ISS score and APACHE II score of patients in the good prognosis group were lower than in the poor prognosis group. In the early stages of trauma, the PCT, CRP and IL-6 in the serum of traumatic shock patients were higher than ordinary trauma patients, also the higher the expression levels of PCT, CRP and IL-6, the worse the prognosis condition. Moreover, CRP has been showing a downward trend in patients with good prognosis. PCT and IL-6 have a short-term rise in the treatment process, and decline subsequently. PCT, CRP, and IL-6 in patients with poor prognosis show an upward trend at the early stage. After maintaining at a higher level, the expression level decreases subsequently.

PCT is a protein secreted by macrophages in the liver after severe infection and major trauma (20), some documents have shown that high expression of PCT in serum is closely related to the occurrence of shock disease (21), monitoring of PCT in patient serum can even predict adverse complications in trauma patients (22). CRP is also a non-specific acute protein synthesized in the liver (23). It is often difficult to detect in serum of ordinary humans, but occurs when the body has an inflammatory reaction (24), it can extremely sensitively reflect the damage of the body tissues and the severity of the infection (25). However, IL-6 can induce acute protein 
responses and mediate body damage in a variety of infectious or acute diseases (26). Some researchers have shown that IL-6 can directly reflect the degree of damage to the body and determine the prognosis of patients (27). Therefore, it is speculated that the high level of serum PCT, CRP and IL-6 in traumatic shock patients may indicate a worse prognosis. This may reflect the activity of inflammation in the body, suggested that there may be an occurrence of systemic inflammatory response syndrome or multiple organ dysfunction syndrome. Increased expression of PCT, CRP, and IL-6 in the serum of patients during the treatment progress indicates that patients may require higher intensity clinical interventions, and require to be highly valued by clinicians.

Due to the limitations of experimental conditions and experimental time of this study, there are still some shortcomings in the experimental design. The sample size of the experiment was not large enough. The molecular mechanism for the specific changes of PCT, CRP and IL- 6 expression levels in patients' serum is still unclear. So animal models need to be constructed for further exploration.

Overall, the higher the expression levels of PCT, CRP and IL-6 in serum of traumatic shock patients, the worse prognosis it may indicate. It has an important reference value for the assessment of traumatic shock patients.

\section{Acknowledgements}

Not applicable.

\section{Funding}

No funding was received.

\section{Availability of data and materials}

The datasets used and/or analyzed during the present study are available from the corresponding author on reasonable request.

\section{Authors' contributions}

YL wrote the manuscript. YL and LC analyzed and interpreted the patient data. WF collected blood samples. HC and YL performed ELISA. All authors read and approved the final manuscript.

\section{Ethics approval and consent to participate}

The study was approved by the Ethics Committee of Zhangzhou Municipal Hospital of Fujian Province (Zhangzhou, China). Patients who participated in this study had complete clinical data. Signed informed consents were obtained from the patients or the guardians.

\section{Patient consent for publication}

Not applicable.

\section{Competing interests}

The authors declare that they have no competing interests.

\section{References}

1. Benjet C, Bromet E, Karam EG, Kessler RC, McLaughlin KA, Ruscio AM, Shahly V, Stein DJ, Petukhova M, Hill E, et al: The epidemiology of traumatic event exposure worldwide: results from the World Mental Health Survey Consortium. Psychol Med 46: 327-343, 2016.

2. Kunitatsu K, Ueda K, Iwasaki Y, Yamazoe S, Yonemitsu T, Kawazoe Y, Kawashima S, Shibata N and Kato S: Outcomes of abdominal trauma patients with hemorrhagic shock requiring emergency laparotomy: efficacy of intra-aortic balloon occlusion. Acute Med Surg 3: 345-350, 2016.

3. Grote S, Böcker W, Mutschler W, Bouillon B and Lefering R: Diagnostic value of the Glasgow Coma Scale for traumatic brain injury in 18,002 patients with severe multiple injuries. J Neurotrauma 28: 527-534, 2011.

4. Yaroustovsky M, Rogalskaya E, Plyushch M, Klimovich L, Samsonova N and Abramyan M: The level of oxidative neutrophil response when determining endotoxin activity assay: a new biomarker for defining the indications and effectiveness of intensive care in patients with sepsis. Int J Inflam 2017: 3495293, 2017.

5. Müller B, Christ-Crain M and Schuetz P: Meta-analysis of procalcitonin for sepsis detection. Lancet Infect Dis 7: 498-499; author reply 502-503, 2007.

6. Zurek J and Vavrina M: Procalcitonin biomarker kinetics to predict multiorgan dysfunction syndrome in children with sepsis and systemic inflammatory response syndrome. Iran J Pediatr 25: e324, 2015.

7. Harrison M: Erythrocyte sedimentation rate and C-reactive protein. Aust Prescr 38: 93-94, 2015.

8. Hunter CA and Jones SA: IL-6 as a keystone cytokine in health and disease. Nat Immunol 16: 448-457, 2015.

9. Máca J, Peteja M, Reimer P, Jor O, Šeděnková V, Panáčková L, Ihnát P, Burda M and Ševčík P: Surgical injury: comparing open surgery and laparoscopy by markers of tissue damage. Ther Clin Risk Manag 14: 999-1006, 2018.

10. Lou X, Lu G, Zhao M and Jin P: Preoperative fluid management in traumatic shock: a retrospective study for identifying optimal therapy of fluid resuscitation for aged patients. Medicine (Baltimore) 97: e9966, 2018.

11. Nieboer P, van der Werf TS, Beentjes JA, Tulleken JE, Zijlstra JG and Ligtenberg JJ: Catecholamine dependency in a polytrauma patient: relative adrenal insufficiency? Intensive Care Med 26: 125-127, 2000.

12. Korać Z, Krajacić I, Hancević J and Marusić Z: Multiple injuries in peacetime and wartime estimate of severity of injury by the Injury Severity Score and Polytraumaschlüssel. Eur J Surg 164: 563-567, 1998.

13. Zhang L, Hu J, Xiao L, Zhang Y, Zhao W, Zheng W and Shang H: Adverse drug reactions of Shenmai injection: a systematic review. J Evid Based Med 3: 177-182, 2010.

14. Okonkwo KC, Wong KG, Cho CT and Gilmer L: Testicular trauma resulting in shock and systemic inflammatory response syndrome: a case report. Cases J 1: 4, 2008.

15. Punyadeera C, Schneider EM, Schaffer D, Hsu HY, Joos TO, Kriebel F, Weiss M and Verhaegh WF: A biomarker panel to discriminate between systemic inflammatory response syndrome and sepsis and sepsis severity. J Emerg Trauma Shock 3: 26-35, 2010.

16. Seymour CW and Rosengart MR: Septic shock: Advances in diagnosis and treatment. JAMA 314: 708-717, 2015.

17. Hofmann N, Zipperle J, Jafarmadar M, Ashmwe M, Keibl C, Penzenstadler C, Ponschab M, Jafarmadar B, Redl H, Bahrami S, et al: Experimental models of endotheliopathy: impact of shock severity. Shock 49: 564-571, 2018.

18. White NJ, Martin EJ, Brophy DF and Ward KR: Examining platelet-fibrin interactions during traumatic shock in a swine model using platelet contractile force and clot elastic modulus. Blood Coagul Fibrinolysis 22: 379-387, 2011.

19. Gür A, Oguzturk H, Köse A, Turtay MG, Ersan V, Bayindir Y, Ince V, Gurbuz $S$ and Yucel N: Prognostic value of procalcitonin, CRP, serum amyloid A, lactate and IL-6 markers in liver transplant patients admitted to ED with suspected infection. In Vivo 31: 1179-1185, 2017.

20. Rule JA, Hynan LS, Attar N, Sanders C, Korzun WJ and Lee WM; Acute Liver Failure Study Group: Procalcitonin identifies cell injury, not bacterial infection, in acute liver failure. PLoS One 10: e0138566, 2015. 
21. Togari H, Sugiyama S, Ogino T, Suzuki S, Ito T, Ichiki T, Kamiya K, Watanabe I, Ogawa Y, Wada Y, et al: Interactions of endotoxin with cortisol and acute phase proteins in septic shock neonates. Acta Paediatr Scand 75: 69-74, 1986.

22. Ahmed AI, Soliman RA and Samir S: Cell free DNA and procalcitonin as early markers of complications in ICU patients with multiple trauma and major surgery. Clin Lab 62: 2395-2404, 2016.

23. Chirapongsathorn S, Bunraksa W, Chaiprasert A, Punpanich D, Supasyndh O and Kamath PS: Adding C-reactive protein and procalcitonin to the model of end-stage liver disease score improves mortality prediction in patients with complications of cirrhosis. J Gastroenterol Hepatol 33: 726-732, 2018.

24. Alexandrov PN, Kruck TP and Lukiw WJ: Nanomolar aluminum induces expression of the inflammatory systemic biomarker C-reactive protein (CRP) in human brain microvessel endothelial cells (hBMECs). J Inorg Biochem 152: 210-213, 2015.
25. Braig D, Nero TL, Koch HG, Kaiser B, Wang X, Thiele JR, Morton CJ, Zeller J, Kiefer J, Potempa LA, et al: Transitional changes in the CRP structure lead to the exposure of proinflammatory binding sites. Nat Commun 8: 14188, 2017.

26. Yang R, Han X, Uchiyama T, Watkins SK, Yaguchi A, Delude RL and Fink MP: IL-6 is essential for development of gut barrier dysfunction after hemorrhagic shock and resuscitation in mice. Am J Physiol Gastrointest Liver Physiol 285: G621-G629, 2003.

27. Gu FM, Li QL, Gao Q, Jiang JH, Zhu K, Huang XY, Pan JF, Yan J, Hu JH, Wang Z, et al: IL-17 induces AKT-dependent IL-6/JAK2/STAT3 activation and tumor progression in hepatocellular carcinoma. Mol Cancer 10: 150, 2011.

(i)(9) This work is licensed under a Creative Commons Attribution-NonCommercial-NoDerivatives 4.0 International (CC BY-NC-ND 4.0) License. 